Kansas State University Libraries

New Prairie Press

\title{
Effect of Correlations on Type 1 Error Rates of Some Multivariate Normality Tests
}

Gbenga Sunday Solomon

gssolomon@student.lautech.edu.ng

Kayode Ayinde

Ladoke Akintola University of Technology,Ogbomoso. Oyo State,Nigeria, kayinde@lautech.edu.ng

Nurudeen Abiodun Alao

Kwara State Polytechnic, alao4nuru@gmail.com

Follow this and additional works at: https://newprairiepress.org/agstatconference

Part of the Applied Statistics Commons, and the Multivariate Analysis Commons

\section{(c) $($ ) $\ominus$}

This work is licensed under a Creative Commons Attribution-No Derivative Works 3.0 License.

\section{Recommended Citation}

We recommend the use of Energy $(\mathrm{E})$ and, or, Henze-Zirkler $(\mathrm{HZ})$ tests for testing assumption of multivariate normality of data before inferential analysis could be carried out.

This Event is brought to you for free and open access by the Conferences at New Prairie Press. It has been accepted for inclusion in Conference on Applied Statistics in Agriculture by an authorized administrator of New Prairie Press. For more information, please contact cads@k-state.edu. 


\title{
Effect of Correlations on Type 1 Error Rates of Some Multivariate Normality Tests
}

By

*11 Gbenga Sunday Solomon, ${ }^{1}$ Kayode Ayinde, ${ }^{2}$ NurudeenAbiodun Alao

${ }^{1,1}$ Department of Statistics,

Ladoke Akintola University of Technology,

P.M.B 4000, LAUTECH, Ogbomoso, Oyo State, Nigeria.

${ }^{2}$ Department of Statistics,

Institute of Applied Sciences, Kwara State Polytechnic,

P.M.B 1375, Ilorin, Kwara State, Nigeria.

Email Address:*1'gssolomon@outlook.com, ${ }^{1}$ kayinde@lautech.edu.ng, ${ }^{2}$ alao4nuru@gmail.com

\begin{abstract}
Normality assumption of multivariate data is a prerequisite to the use of multivariate statistical data analysis methods before inference could be valid and reliable. Tests developed to validate this assumption including Doornik-Harsen (DH), Shapiro-Francia (SF), Mardia Skewness (MS), Mardia Skewness for small sample (MSS) and Kurtosis (MK), Skewness (S) and Kurtosis(K), ShapiroWilk(SW), Royston (R), Desgagne-Micheaux (DM), Henze-Zirkler (HZ), Energy (E), GelGastwirth (GG) and Bontemps-Meddahi (BM) tests often result into different conclusions. These differences can be misleading. Consequently, this paper examined the effect of correlations on the Type 1 error rates of multivariate tests of normality. Monte Carlo experiments were conducted one thousand (1000) times taking into consideration the dimensions, correlations and sample sizes of the multivariate data. A test is affected by correlation if its estimated Type 1 error rate changes as correlation changes. A test is considered good if its estimated error rate approximates the true error rate and best if the number of times it approximates the estimated error rate when counted over the levels of correlations, sample sizes and levels of significance is the highest, the mode. Results show that Type 1 error rates of DH, SF, SW, R, DM, GG and BM tests are affected by correlations and are relatively not good; whereas the Type 1 error rates of HZ, MS, MK, MSS, S, K and E tests are not only unaffected by correlations but are also relatively good. Consequently, MS, R, MSS, HZ and $\mathrm{E}$ tests have good Type 1 error rates but that of $\mathrm{E}$ and $\mathrm{HZ}$ tests are best. They are therefore recommended for practitioners.
\end{abstract}

Key Words: Correlation, Level of Significance, Type 1 error rate, Multivariate Normality test

\subsection{Introduction}

Multivariate inferential statistical methods including Hotelling's $\mathrm{T}^{2}$ tests, Multivariate Analysis of Variance (MANOVA), Multivariate Analysis of Covariance (MANCOVA), Canonical Correlation, Multivariate Regression Analysis and Discriminant Analysis depend on the assumption of multivariate normality of data before inference about their parameters could be valid and reliable. New Prairieppessinstance, the residuals from a multivariate linear regression model are required to be normally 
distributed for inference on the parameters to be valid. If they are not normally distributed then inference about the parameters are inappropriate [1].

Several tests of multivariate normality including: Doornik-Harsen (DH) [2], Shapiro-Francia (SF) [3], Mardia Skewness (MS), Mardia Skewness for small sample (MSS) and Kurtosis (MK) [4], Skewness (S) and Kurtosis (K) [5], Shapiro-Wilk (SW) [6], Royston (R) [7], Desgagne-Micheaux (DM) [8], Henze-Zirkler (HZ) [9], Energy (E) [10], Gel-Gastwirth (GG) [11] and BontempsMeddahi (BM) [12] have therefore been developed.

A major problem encountered with the use of these tests is that their results are seldom the same. A probable cause may be that the strength of inter-correlations that exist between the multivariate data affects the performance of some of these multivariate tests of normality. Consequently, the study was carried out to examine the effect of correlations on the Type 1 error rates of multivariate tests of normality so as to identify the stable ones and recommend them to users appropriately.

\subsection{Review of Multivariate Tests of Normality}

Thorough study of the literature reveals that several developed tests for assessing multivariate normality (MVN) exist. These tests were reviewed in [13] as follows.

\subsection{Desgagne-Micheaux Multivariate Normality Test}

Desgagné, Micheaux and Leblanc [8] proposed a new multivariate normality tests based on the distribution defined as:

$$
g(x ; \theta)=k(\theta) \ell^{-\frac{1}{2}|x|^{\theta_{1}}}(1+|x|)^{-\theta_{2}}(\log (\ell+|x|))^{-\theta_{3}}
$$

where $\theta=\left(\theta_{1}, \theta_{2}, \theta_{3}\right)^{\prime}$, the vector of parameters, and $k(\theta)$ is the normalizing constant. $\theta_{1} \in \mathfrak{R}^{+}, x, \theta_{2}, \theta_{3} \in \mathfrak{R}$.

The proposed multivariate normality test according to [8] is given as:

$R_{n}=n r_{n}\left(\bar{X}_{n}, S_{n}\right)^{T}\left(J_{0}-\frac{1}{2} v_{0} v_{0}^{T}\right)^{-1} r_{n}\left(\bar{X}_{n}, S_{n}\right) \sim \chi_{3}^{2}$

Where $r_{n}\left(\bar{X}_{n}, S_{n}\right)=r_{n}(\mu, \sigma)-\frac{1}{2}\left(1-T_{n}\right) \nu_{0}+O_{P}\left(n^{-1 / 2}\right) 1_{3}, r_{n}(\mu, \sigma)=\frac{1}{n} \sum_{i=1}^{n} d_{0}\left(Y_{i}\right), Y_{i}=\frac{X_{i}-\mu}{\sigma}$

$$
\begin{aligned}
& T_{n}=\frac{1}{n} \sum_{i=1}^{n} Y_{i}^{2}, 1_{3}=\left(\begin{array}{lll}
1 & 1 & 1
\end{array}\right)^{T}, J_{0}=E_{0}\left[d_{0}(Y) d_{0}(Y)^{T}\right], d_{0}(Y)=\left.\frac{\partial}{\partial \theta} \log g(y ; \theta)\right|_{\theta=\left(\begin{array}{lll}
2 & 0 & 0
\end{array}\right)^{T}} \\
& v_{0}=-E_{0}\left[Y^{2} d_{0}(Y)\right]
\end{aligned}
$$

\subsection{Mardia's Measures of Multivariate Kurtosis and Skewness}

Let $X_{1}, X_{2}, \cdots, X_{p}$ be independent n-dimensional random vectors of an identical distribution. Let $p$ , $\bar{X}_{n}$ and $S$ be the multivariate dimension, mean and covariance matrix. That is $\bar{X}_{n}=n^{-1} \sum_{i=1}^{n} X_{i}$ and $S=\frac{1}{n} \sum_{i=1}^{n}\left(X_{i}-\bar{X}_{n}\right)\left(X_{i}-\bar{X}_{n}\right)^{T}$. Then Mardia's measure of multivariate kurtosis and skewness proposed by [14] are as follows:

$\underset{k}{k}=\frac{1}{\sum_{i=1}^{n}}\left[\left(X_{i}-\bar{X}_{n}\right)^{T} S^{-1}\left(X_{i}-\bar{X}_{n}\right)\right]^{2}$ 


$$
\begin{aligned}
& \frac{k-[p(p+2)(n-1) /(n+1)]}{[8 p(p+2) / n]^{0.5}} \sim N(0,1) \\
& s=\frac{1}{n^{2}} \sum_{i=1}^{n} \sum_{j=1}^{n}\left[\left(X_{i}-\bar{X}_{n}\right)^{T} S^{-1}\left(X_{i}-\bar{X}_{n}\right)\right]^{3} \\
& \frac{n s}{6} \sim \chi_{p(p+1)(p+2) / 6}^{2}
\end{aligned}
$$

\subsection{Henze-Zirkler Test}

The test proposed by Henze and Zirkler in [15] is discussed as follows:

$$
\left.\left.T_{n, \beta}=\frac{1}{n} \sum_{k=1}^{n} \sum_{j=1}^{n}\left[\ell^{\left(-\frac{\beta^{2}}{2}\left\|Y_{j}-Y_{k}\right\|^{2}\right.}\right)\right]-2\left(1+\beta^{2}\right)^{-p / 2} \times \sum_{j=1}^{n}\left[e^{\left(-\frac{\beta^{2}}{2\left(1+\beta^{2}\right)}\left\|Y_{j}\right\|^{2}\right.}\right)\right]+n\left(1+2 \beta^{2}\right)^{-p / 2}
$$

where $\left\|Y_{j}-Y_{k}\right\|^{2}=\left(X_{j}-X_{k}\right)^{T} S^{-1}\left(X_{j}-X_{k}\right),\left\|Y_{j}\right\|^{2}=\left(X_{j}-\bar{X}_{n}\right)^{T} S^{-1}\left(X_{j}-\bar{X}_{n}\right)$

$$
\begin{aligned}
& \beta=\frac{1}{\sqrt{2}}\left(\frac{2 p+1}{4}\right)^{1 /(p+4)} n^{1 /(p+4)}, T_{n, \beta} \sim \ln N\left(E\left[T_{\beta}\right\rfloor \operatorname{Var}\left[T_{\beta} \mid\right)\right. \\
& E\left[T_{\beta}\right]=1-\left(1+2 \beta^{2}\right)^{-p / 2}\left[\frac{1+p \beta^{2}}{1+2 \beta^{2}}+\frac{p(p+2) \beta^{4}}{2\left(1+2 \beta^{2}\right)^{2}}\right] \\
& \operatorname{Var}\left[T_{\beta}\right]=2\left(1+4 \beta^{2}\right)^{-p / 2}+2\left(1+2 \beta^{2}\right)^{-p}\left[\frac{1+2 p \beta^{4}}{\left(1+2 \beta^{2}\right)^{2}}+\frac{3 p(p+2) \beta^{8}}{4\left(1+2 \beta^{2}\right)^{4}}\right] \\
& -4 w(\beta)^{-p / 2}\left[1+\frac{3 p \beta^{4}}{2 w(\beta)}+\frac{p(p+2) \beta^{8}}{2 w\left(\beta^{2}\right)}\right]
\end{aligned}
$$

where $w(\beta)=\left(1+\beta^{2}\right)\left(1+3 \beta^{2}\right)$.

\section{$2.4 \quad$ Royston's H Test}

Royston's $H$ test [7] is defined as

$$
H=\xi \sum_{j} \frac{R_{j}}{p} \sim \chi_{\xi}^{2}
$$

where $\xi=\frac{p}{[1+(p-1) \bar{c}]}, \quad R_{j}=\left\{\Phi^{-1}\left[\frac{1}{2} \Phi\left\{\left(\left(1-W_{j}\right)^{2}-\mu\right) / \sigma\right\}\right]\right\}^{2}, W_{j}$ is the Shapiro-Wilk statistic. $\lambda, \mu$, and $\sigma$ are determined from the polynomial approximations given in [16].

\subsection{The Energy Test for Multivariate Normality}

The multivariate energy test proposed by Szekely and Rizzo [10] is defined as follows:

$$
E=n\left[\frac{2}{n} \sum_{i=1}^{n} \mathrm{E}\left\|Y_{i}^{*}-Z\right\|-E\left\|Z-Z^{T}\right\|-\frac{1}{n^{2}} \sum_{i=1}^{n}\left\|Y_{i}^{*}-Y_{j}^{*}\right\|\right]
$$

where $Y_{i}^{*}, i=1,2, \ldots, n$ is the standardized sample, $Z$ and $Z^{T}$ are independently and identically distributed (i.i.d) $p$ - variate standard normal random vectors.

\subsection{Generalized Shapiro-Wilk Test}

The generalized Shapiro-Wilk test according to Czeslaw [17] is given as:

$$
W_{p}=\frac{\left\{\sum_{i=1}^{h} a_{(i, n)}\left(U_{(n-i+1)}-U_{(i)}\right)\right\}^{2}}{\left(X_{m}-\bar{X}\right)^{T} A^{-1}\left(X_{j}-\bar{X}\right)^{T}}
$$


where $U_{j}=\left(X_{m}-\bar{X}\right)^{T} A^{-1}\left(X_{j}-\bar{X}\right)$ for $j=1,2, \cdots, n, A=\sum_{j=1}^{n}\left(X_{j}-\bar{X}\right)\left(X_{j}-\bar{X}\right)^{T}, h=\frac{n}{2}$ if $\mathrm{n}$ is even and $h=\frac{(n-1)}{2}$ if $\mathrm{n}$ is odd, $a_{(i, n)}(i=1,2, \cdots, h)$.

The test could be compared with a quantile of the rank $\alpha$ of the Shapiro-Wilk distribution as thus; Reject the hypothesis if $W_{p}<W_{p}^{\alpha}$ where the critical value is $W_{p}^{\alpha}$ [17].

\subsection{Doornik-Harsen Test}

Doornik and Harsen test [2] is discussed as follows: compute univariate skewness and kurtosis of each normally distributed transformed $n$-vector of observations

$\frac{n B_{1}^{\prime} B_{1}}{6}+\frac{n\left(B_{2}-3 \imath\right)^{\prime}\left(B_{2}-3 \imath\right)}{24} \sim \chi_{\alpha}^{2}(2 p)$

where $B_{1}^{\prime}=\left(\sqrt{b_{11}}, \cdots, \sqrt{b_{1 P}}\right), B_{2}^{\prime}=\left(b_{21}, \cdots, b_{2 p}\right)$ and $\imath$ is a $p$-vectorof ones. After the transformation of the data to independent normals, the univariate test is then applied to each dimension [2]. Let $Z_{1}^{\prime}=\left(z_{11}, \cdots, z_{1 p}\right)$ and $Z_{2}^{\prime}=\left(z_{21}, \cdots, z_{2 p}\right)$. Then the proposed test is:

$$
E_{p}=Z_{1}^{\prime} Z_{1}+Z_{2}^{\prime} Z_{2} \sim \chi_{\alpha}^{2}(2 p)
$$

\subsection{Skewness (S) and Kurtosis (K) tests}

The proposed tests of multivariate kurtosis and skewness by [5] are given below. The test for kurtosis is:

$W=\left[\operatorname{Tr}\left(\left(C_{1}^{-1} C_{2}\right)^{2}\right)-\frac{1}{p} \operatorname{Tr}^{2}\left(C_{1}^{-1} C_{2}\right)\right]+\frac{1}{p}\left[\operatorname{Tr}\left(C_{1}^{-1} C_{2}\right)-p\right]^{2} \sim \chi_{p(p+1) / 2}^{2}$

$C_{1}$ and $C_{2}$ are two separate scatter matrices equipped with the correction factor.

The test for skewness is:

$U=\left(T_{1}-T_{2}\right)^{T} C^{-1}\left(T_{1}-T_{2}\right) \sim \chi_{p}^{2}$

where $T_{1}$ and $T_{2}$ are two separate location vectors, and $C$ a scatter matrix.

\subsection{The Bontemps-Meddahi test}

The family of normality tests proposed by Bontemps and Meddahi [12] is give as: $B M_{3-d}=\sum_{k=3}^{d}\left(\frac{1}{\sqrt{n}} \sum_{i=1}^{n} H_{k}\left(z_{i}\right)\right)^{2} \sim \chi_{d-2}^{2}$

where $H_{k}(\cdot)$ is the $k$ th order normalized Hermite polynomial and $z_{i}=\frac{\left(x_{i}-\bar{x}\right)}{s}$.

\subsection{Methodology}

The investigation of how correlations affect the Type 1 error rates of the multivariate tests of normality are examined via Monte Carlo study in connection with the equation proposed in [18] defined according to equation 14 . For example with $p=5$, the equation becomes: 


$$
\begin{aligned}
& {\left[\begin{array}{l}
X_{1} \\
X_{2} \\
X_{3} \\
X_{4} \\
X_{5}
\end{array}\right]=\left[\begin{array}{l}
\mu_{1} \\
\mu_{2} \\
\mu_{3} \\
\mu_{4} \\
\mu_{5}
\end{array}\right]+\left[\begin{array}{ccccc}
\gamma_{11} & 0 & 0 & 0 & 0 \\
\gamma_{12} & \gamma_{22} & 0 & 0 & 0 \\
\gamma_{13} & \gamma_{23} & \gamma_{33} & 0 & 0 \\
\gamma_{14} & \gamma_{24} & \gamma_{34} & \gamma_{44} & 0 \\
\gamma_{15} & \gamma_{25} & \gamma_{35} & \gamma_{45} & \gamma_{55}
\end{array}\right]\left[\begin{array}{l}
Z_{1} \\
Z_{2} \\
Z_{3} \\
Z_{4} \\
Z_{5}
\end{array}\right]} \\
& X_{1}=\mu_{1}+\gamma_{11} Z_{1} \\
& X_{2}=\mu_{2}+\gamma_{12} Z_{1}+\gamma_{22} Z_{2} \\
& X_{3}=\mu_{3}+\gamma_{13} Z_{1}+\gamma_{23} Z_{2}+\gamma_{33} Z_{3} \\
& X_{4}=\mu_{4}+\gamma_{14} Z_{1}+\gamma_{24} Z_{2}+\gamma_{34} Z_{3}+\gamma_{44} Z_{4} \\
& X_{5}=\mu_{5}+\gamma_{15} Z_{1}+\gamma_{25} Z_{2}+\gamma_{35} Z_{3}+\gamma_{45} Z_{4}+\gamma_{55} Z_{5}
\end{aligned}
$$

where

$$
\begin{aligned}
& \gamma_{11}=\sigma_{1}, \gamma_{12}=\rho_{12} \sigma_{2}, \gamma_{13}=\rho_{13} \sigma_{3}, \gamma_{14}=\rho_{14} \sigma_{4}, \gamma_{15}=\rho_{15} \sigma_{5} \\
& \gamma_{22}=\sqrt{\sigma_{2}^{2}-\gamma_{12}^{2}}, \gamma_{23}=\frac{\rho_{23} \sigma_{2} \sigma_{3}-\gamma_{12} \gamma_{13}}{\gamma_{22}}, \gamma_{24}=\frac{\rho_{24} \sigma_{2} \sigma_{4}-\gamma_{12} \gamma_{14}}{\gamma_{22}} \\
& \gamma_{25}=\frac{\rho_{25} \sigma_{2} \sigma_{5}-\gamma_{12} \gamma_{15}}{\gamma_{22}}, \gamma_{33}=\sqrt{\sigma_{3}^{2}-\gamma_{13}^{2}-\gamma_{23}^{2}}, \gamma_{34}=\frac{\rho_{34} \sigma_{3} \sigma_{4}-\gamma_{13} \gamma_{14}-\gamma_{23} \gamma_{24}}{\gamma_{33}} \\
& \gamma_{35}=\frac{\rho_{35} \sigma_{3} \sigma_{5}-\gamma_{13} \gamma_{15}-\gamma_{23} \gamma_{25}}{\gamma_{33}}, \gamma_{44}=\sqrt{\sigma_{4}^{2}-\gamma_{14}^{2}-\gamma_{24}^{2}-\gamma_{34}^{2}} \\
& \gamma_{45}=\frac{\rho_{45} \sigma_{4} \sigma_{5}-\gamma_{14} \gamma_{15}-\gamma_{24} \gamma_{25}-\gamma_{34} \gamma_{35}}{\gamma_{44}} \text { and } \gamma_{55}=\sqrt{\sigma_{5}^{2}-\gamma_{15}^{2}-\gamma_{25}^{2}-\gamma_{35}^{2}-\gamma_{45}^{2}}
\end{aligned}
$$

The parameters for the Monte Carlo simulation study are: seven levels of inter-correlations namely $\rho_{i j}=\rho=0,0.3,0.6,0.8,0.9,0.95$, and $0.99 \forall i=1,2, \cdots, p$ and $j=1,2, \cdots, p$, four levels of dimension, $p=2,3,4$ and 5, eight sample sizes $\mathrm{n}=10,20,30,50,75,100,150$ and 300, three levels of significance, $\alpha=0.1,0.05$ and 0.01 .

The simulation procedure is according to the procedure outlined in [19]. We generated 1000 (Replications $(\mathrm{K})$ ) set of multivariate normally distributed samples using the specified values of $p$ and $n$ from R-program environment [20]. The generated data were then subjected to the multivariate normality tests and the associated p-values as a result of the tests were documented at each stage of the replications. Let

$$
S_{i}= \begin{cases}1, & \text { if } p-\text { value }<\alpha \\ 0, & \text { Otherwise }\end{cases}
$$

$$
\forall i=1,2, \cdots, K
$$

Define $S=\sum_{i=1}^{K} S_{i}$, then the estimated Type 1 error rate is given as:

$$
E_{\alpha}=\frac{S}{K}
$$

The method was repeated until all the parameters for the simulation were completely utilized. A multivariate test of normality is affected by correlation if its estimated Type 1 error rate changes as level of correlation changes. It is stable if as correlation changes the Type 1 error rates remain the New Prairieanese. Furthermore, a test is considered good if its estimated error rates approximates the true error 
rate, and best if its empirical Type 1 error rates approximates the true error rates most often (Highest frequency) when counted over the three levels of significance. A test with an error rate outside of ranges presented in Table 1 is considered comparatively 'not good'.

Table 1: The True Level of Significance and Their Preferred Interval

\begin{tabular}{cl}
\hline True levels of significance & Preferred interval \\
\hline 0.1 & $0.095-0.14$ \\
0.05 & $0.045-0.054$ \\
0.01 & $0.005-0.014$ \\
\hline
\end{tabular}

Source: [13] \& [21]

\subsection{Results and Discussion}

The results of effect of correlations on Type 1 error rates of multivariate normality tests for the levels of significance, correlations, dimensions and sample sizes from the empirical data available in [19] are presented and discussed. The results show that Type 1 error rates of some normality tests are affected by correlations.

The results at 0.1 level of significance is presented in Figure 1 (see Table 2 for sample data). It was observed that the Type 1 error rates of $\mathrm{DH}, \mathrm{GG}, \mathrm{BM}$ and $\mathrm{DM}$ increase as correlations increase. Type 1 error rates of R, HZ, MS, MK, MSS, S, K, SW, SF and E are not affected by correlations. Type 1 error rates of DH, GG, BM, DM, SW and SF are comparatively not good but that of R, HZ, MS, MK, MSS, S, K, and E are comparatively good. Results from counting the number of times Type 1 error rates approximate 0.1 show that: Type 1 error rates of MS, MK, DH, S, K, SW, SF, GG, BM and DM tests are relatively not good at almost all sample sizes while that of HZ, MSS, R and E tests are reasonably good at almost all sample sizes. Therefore, R, E, MSS and HZ tests in this order perform well.

The results at 0.05 level of significance is displayed in Figure 2 (see Table 3 for sample data), the results show that: the Type 1 error rates of HZ, MS, MK, R, K, MSS, S, SW, SF and E are not affected by correlations. Type 1 error rates of DM, BM, GG, and DH increase as correlations increase. As sample sizes and dimensions increase, the effect correlations on the tests Type 1 error rates becomes more pronounced. Type 1 error rates of HZ, MS, MK, R, K, MSS, S, and E revolve around 0.05. Type 1 error rates of GG, BM, DH, DM, SW and SF are comparatively not good. Results from counting the number of times Type 1 error rates approximate 0.05 revealed that: Type 1 error rates of all the tests are generally not good. Type 1 error rate of MS is good for sample size greater than or equal to 75 except at 300.E test has good Type 1 error rates for sample size 10.

The result of effect of correlations on Type 1 error rates examined at 0.01 level of significance is presented in Figure 3 (See Table 4 for sample data). It was observed that the Type 1 error rates of R, K, MSS, HZ, MS, MK, S, SW, SF and E are not affected by correlations. At lower dimensions, 
Type 1 error rates of BM, GG, DM, and DH reduce and converge to 0.01 as correlations Kansas State while the same increases at higher dimension as correlation increase. As sample sizes and dimensions increase, the effect of the correlations on the tests Type 1 error rates is more noticeable. Type 1 error rates of R, K, MSS, HZ, MS, MK, S, and E revolve around 0.01 at all sample sizes. The Type 1 error rates of BM, DH, DM, GG, SF and SW are comparatively not good at this level. Results from counting the number of times Type 1 error rates approximate 0.01 revealed that the Type 1 error rates of GG, BM, DG, SW, SF, K, DH tests are relatively not good at almost all sample sizes while that of MS is good for sample sizes 20 to 100. Also, the Type 1 error rates of MK is good for sample size of at least 50 while it is not good for sample sizes less than or equal to 300. Furthermore, HZ, S and E tests have good Type 1 error rates at almost all sample sizes but Type 1 error rates of $\mathrm{S}$ is not good for sample sizes less than or equal to 30 while Type 1 error rates of $\mathrm{HZ}$ is not good at sample size 10.

Table 5 shows the overall total number of times Type 1 error rates of the multivariate normality tests approximated true levels of significance when counted over levels of significance, dimensions and levels of correlations. A maximum count of 84 is expected from each of the tests at each sample level. The result shows that the Type 1 error rates of MS, MK, DH, S, K, SW, SF, GG, BM and DM tests are generally not good for sample sizes less than or equal to 30.Type 1 error rates of E and $\mathrm{HZ}$ tests are good at all sample sizes except at sample size of 10 where that of $\mathrm{HZ}$ deviates. Type 1 error rates of MSS test are fair at almost all sample sizes. Having further counted over sample sizes, critical analysis of the results show that MS, R, MSS, HZ and E tests have good Type 1 error rates behavior in that order. It should be noted that total overall expected maximum count is 672. The results are presented in Figure 4. 


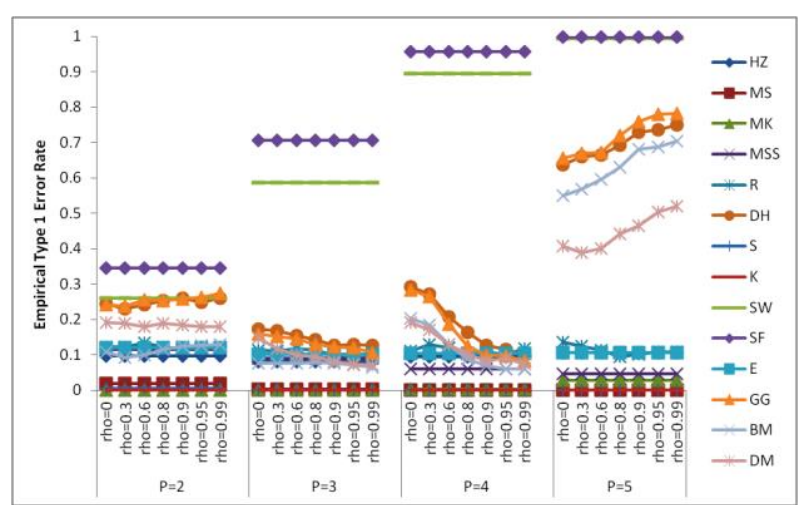

(a) $\mathrm{n}=10$ at $\alpha=0.1$

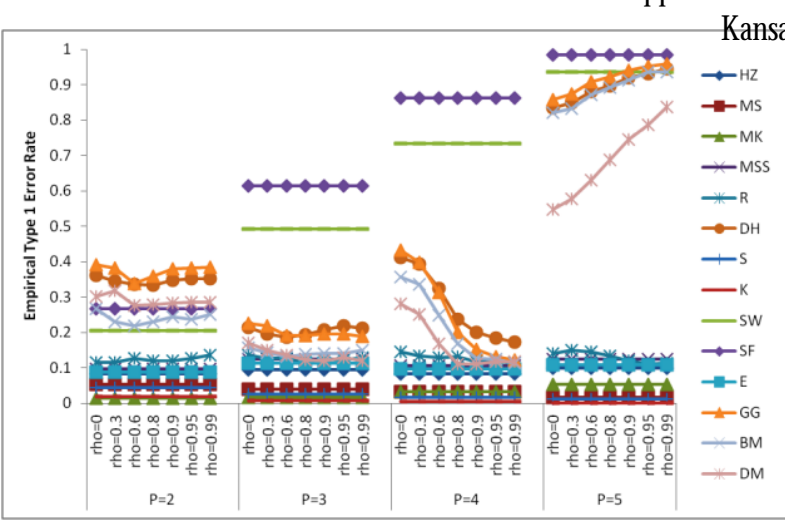

(b) $\mathrm{n}=20$ at $\alpha=0.1$

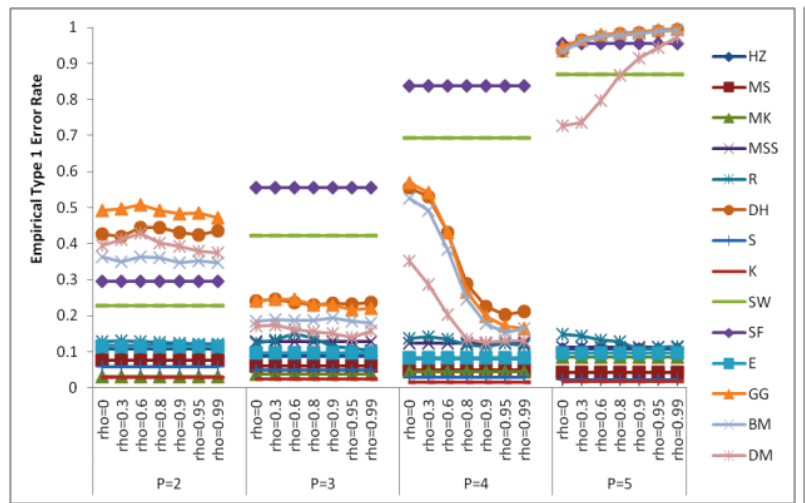

(c) $\mathrm{n}=30$ at $\alpha=0.1$

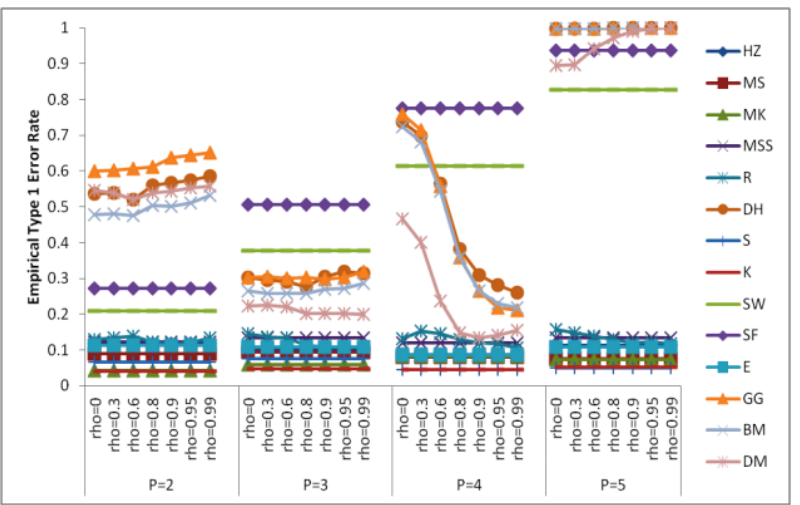

(d) $\mathrm{n}=50$ at $\alpha=0.1$

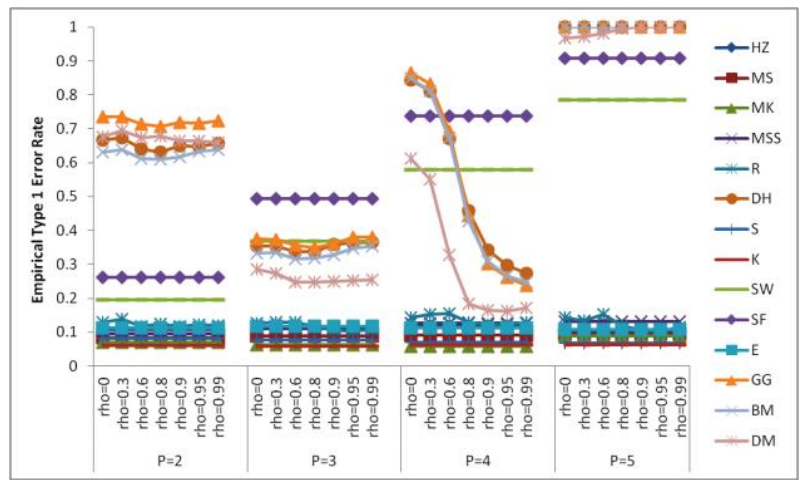

(e) $\mathrm{n}=75$ at $\alpha=0.1$

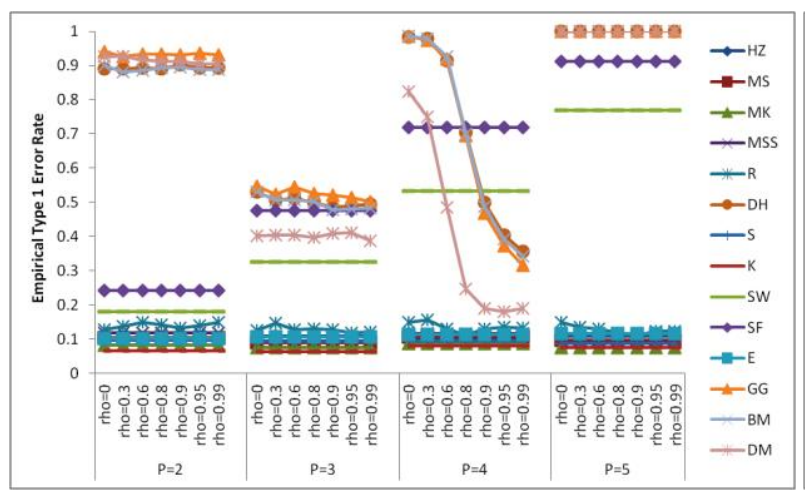

(g) $\quad \mathrm{n}=150$ at $\alpha=0.1$

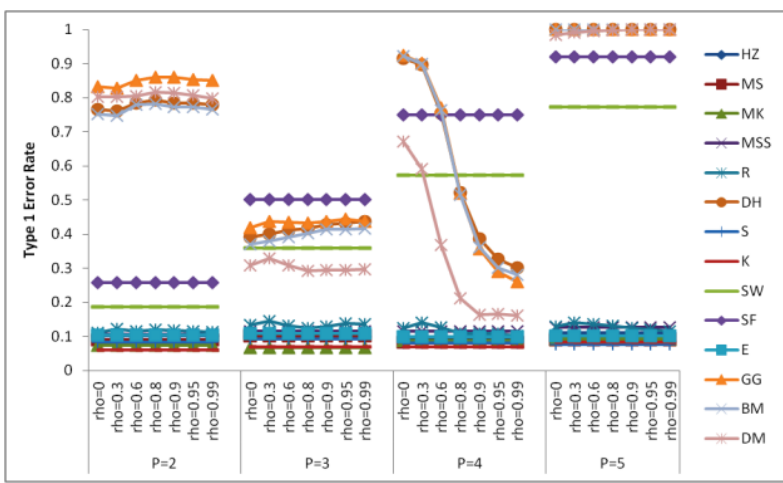

(f) $\quad \mathrm{n}=100$ at $\alpha=0.1$

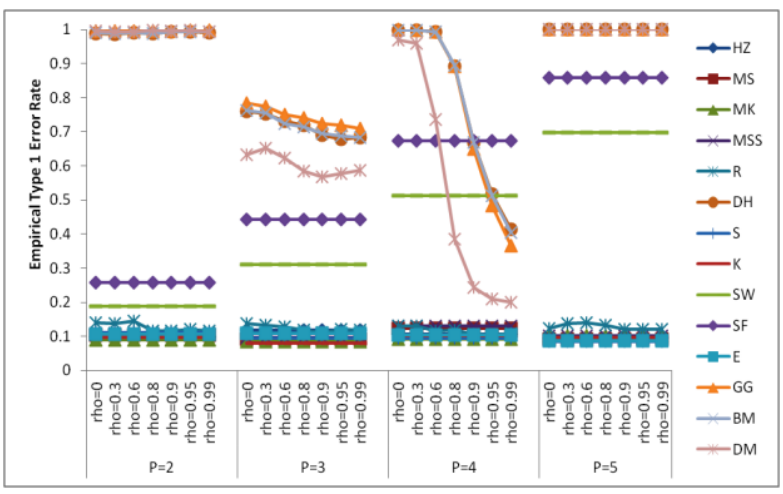

(h) $\quad \mathrm{n}=300$ at $\alpha=0.1$

Figure 1: Comparison of Type 1 Error Rates of Multivariate Normality Tests in the Presence of Correlation at 0.1 Level of Significance 
Table 2: Sample of Empirical Type 1 Error Rate for Comparison of Multivariate Normality Kansas State University $10 \%$ Level of Significance

\begin{tabular}{|c|c|c|c|c|c|c|c|c|c|c|}
\hline \multicolumn{2}{|c|}{ Sample Size } & \multicolumn{4}{|c|}{10} & \multicolumn{5}{|c|}{20} \\
\hline Test & plrho & 0 & 0.6 & 0.9 & 0.99 & 0 & 0.6 & 0.9 & 0.95 & 0.99 \\
\hline \multirow{3}{*}{$\mathrm{HZ}$} & 2 & 0.096 & 0.096 & 0.096 & 0.096 & 0.084 & 0.084 & 0.084 & 0.084 & 0.084 \\
\hline & 3 & 0.08 & 0.08 & 0.08 & 0.08 & 0.094 & 0.094 & 0.094 & 0.094 & 0.094 \\
\hline & 4 & 0.094 & 0.094 & 0.094 & 0.094 & 0.082 & 0.082 & 0.082 & 0.082 & 0.082 \\
\hline \multirow{3}{*}{ MS } & 2 & 0.019 & 0.019 & 0.019 & 0.019 & 0.054 & 0.054 & 0.054 & 0.054 & 0.054 \\
\hline & 3 & 0.002 & 0.002 & 0.002 & 0.002 & 0.04 & 0.04 & 0.04 & 0.04 & 0.04 \\
\hline & 4 & 0 & 0 & 0 & 0 & 0.033 & 0.033 & 0.033 & 0.033 & 0.033 \\
\hline \multirow{3}{*}{ MK } & 2 & 0 & 0 & 0 & 0 & 0.014 & 0.014 & 0.014 & 0.014 & 0.014 \\
\hline & 3 & 0 & 0 & 0 & 0 & 0.016 & 0.016 & 0.016 & 0.016 & 0.016 \\
\hline & 4 & 0.002 & 0.002 & 0.002 & 0.002 & 0.033 & 0.033 & 0.033 & 0.033 & 0.033 \\
\hline \multirow{3}{*}{ MSS } & 2 & 0.116 & 0.116 & 0.116 & 0.116 & 0.097 & 0.097 & 0.097 & 0.097 & 0.097 \\
\hline & 3 & 0.09 & 0.09 & 0.09 & 0.09 & 0.124 & 0.124 & 0.124 & 0.124 & 0.124 \\
\hline & 4 & 0.06 & 0.06 & 0.06 & 0.06 & 0.106 & 0.106 & 0.106 & 0.106 & 0.106 \\
\hline \multirow{3}{*}{$\mathrm{R}$} & 2 & 0.123 & 0.133 & 0.115 & 0.119 & 0.116 & 0.126 & 0.12 & 0.126 & 0.136 \\
\hline & 3 & 0.113 & 0.117 & 0.099 & 0.1 & 0.135 & 0.127 & 0.124 & 0.123 & 0.129 \\
\hline & 4 & 0.11 & 0.119 & 0.109 & 0.118 & 0.145 & 0.13 & 0.118 & 0.117 & 0.115 \\
\hline \multirow{3}{*}{$\mathrm{DH}$} & 2 & 0.245 & 0.242 & 0.259 & 0.261 & 0.36 & 0.336 & 0.347 & 0.353 & 0.353 \\
\hline & 3 & 0.173 & 0.155 & 0.127 & 0.126 & 0.214 & 0.187 & 0.208 & 0.218 & 0.211 \\
\hline & 4 & 0.291 & 0.206 & 0.126 & 0.098 & 0.412 & 0.325 & 0.2 & 0.185 & 0.172 \\
\hline \multirow{3}{*}{$S$} & 2 & 0.004 & 0.004 & 0.004 & 0.004 & 0.044 & 0.044 & 0.044 & 0.044 & 0.044 \\
\hline & 3 & 0 & 0 & 0 & 0 & 0.026 & 0.026 & 0.026 & 0.026 & 0.026 \\
\hline & 4 & 0 & 0 & 0 & 0 & 0.016 & 0.016 & 0.016 & 0.016 & 0.016 \\
\hline \multirow{3}{*}{ K } & 2 & 0 & 0 & 0 & 0 & 0.018 & 0.018 & 0.018 & 0.018 & 0.018 \\
\hline & 3 & 0 & 0 & 0 & 0 & 0.007 & 0.007 & 0.007 & 0.007 & 0.007 \\
\hline & 4 & 0 & 0 & 0 & 0 & 0.004 & 0.004 & 0.004 & 0.004 & 0.004 \\
\hline \multirow{3}{*}{ SW } & 2 & 0.26 & 0.26 & 0.26 & 0.26 & 0.204 & 0.204 & 0.204 & 0.204 & 0.204 \\
\hline & 3 & 0.586 & 0.586 & 0.586 & 0.586 & 0.493 & 0.493 & 0.493 & 0.493 & 0.493 \\
\hline & 4 & 0.895 & 0.895 & 0.895 & 0.895 & 0.733 & 0.733 & 0.733 & 0.733 & 0.733 \\
\hline \multirow{3}{*}{$\mathrm{SF}$} & 2 & 0.346 & 0.346 & 0.346 & 0.346 & 0.268 & 0.268 & 0.268 & 0.268 & 0.268 \\
\hline & 3 & 0.707 & 0.707 & 0.707 & 0.707 & 0.615 & 0.615 & 0.615 & 0.615 & 0.615 \\
\hline & 4 & 0.956 & 0.956 & 0.956 & 0.956 & 0.863 & 0.863 & 0.863 & 0.863 & 0.863 \\
\hline \multirow{3}{*}{$\mathrm{E}$} & 2 & 0.119 & 0.119 & 0.119 & 0.119 & 0.087 & 0.087 & 0.087 & 0.087 & 0.087 \\
\hline & 3 & 0.102 & 0.102 & 0.102 & 0.102 & 0.113 & 0.113 & 0.113 & 0.113 & 0.113 \\
\hline & 4 & 0.104 & 0.104 & 0.104 & 0.104 & 0.097 & 0.097 & 0.097 & 0.097 & 0.097 \\
\hline \multirow{3}{*}{ GG } & 2 & 0.241 & 0.255 & 0.258 & 0.273 & 0.39 & 0.337 & 0.379 & 0.381 & 0.383 \\
\hline & 3 & 0.158 & 0.145 & 0.123 & 0.107 & 0.225 & 0.19 & 0.195 & 0.196 & 0.188 \\
\hline & 4 & 0.283 & 0.186 & 0.099 & 0.084 & 0.433 & 0.313 & 0.153 & 0.131 & 0.121 \\
\hline \multirow{3}{*}{$\mathrm{BM}$} & 2 & 0.108 & 0.098 & 0.124 & 0.13 & 0.266 & 0.219 & 0.245 & 0.236 & 0.25 \\
\hline & 3 & 0.076 & 0.077 & 0.075 & 0.065 & 0.157 & 0.131 & 0.141 & 0.141 & 0.149 \\
\hline & 4 & 0.202 & 0.128 & 0.068 & 0.059 & 0.357 & 0.249 & 0.126 & 0.125 & 0.112 \\
\hline \multirow{3}{*}{$\mathrm{DM}$} & 2 & 0.192 & 0.179 & 0.183 & 0.18 & 0.302 & 0.277 & 0.282 & 0.285 & 0.286 \\
\hline & 3 & 0.147 & 0.098 & 0.081 & 0.071 & 0.171 & 0.136 & 0.12 & 0.13 & 0.12 \\
\hline & 4 & 0.19 & 0.129 & 0.084 & 0.073 & 0.28 & 0.168 & 0.11 & 0.117 & 0.118 \\
\hline
\end{tabular}

Source: Simulation Results available in [19] 


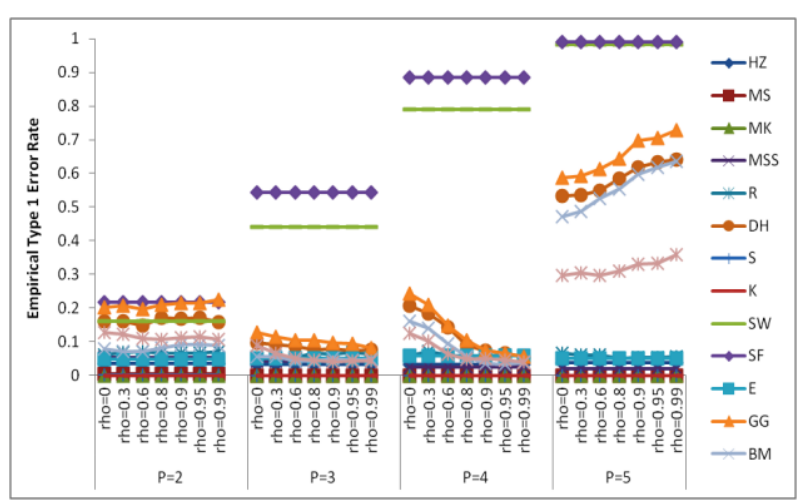

(a) $\mathrm{n}=10$ at $\alpha=0.05$

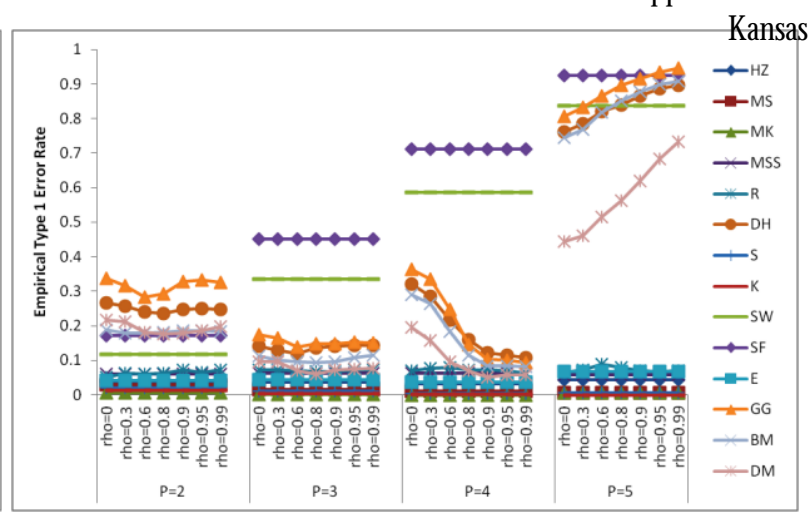

(b)

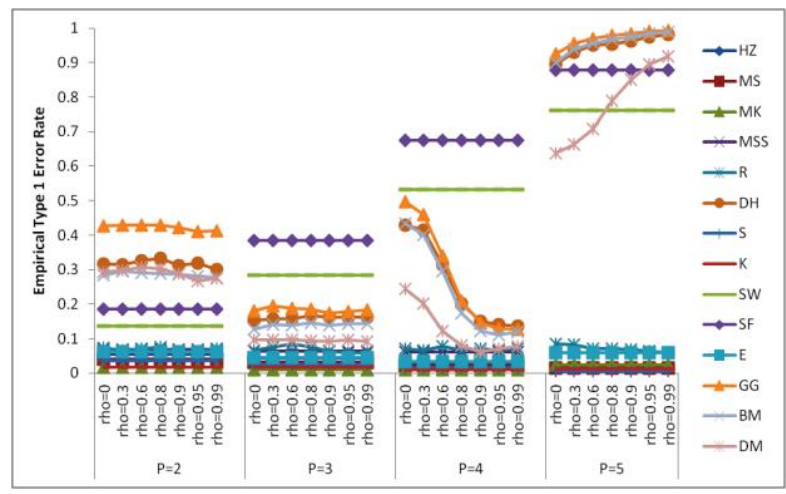

(c) $\mathrm{n}=30$ at $\alpha=0.05$

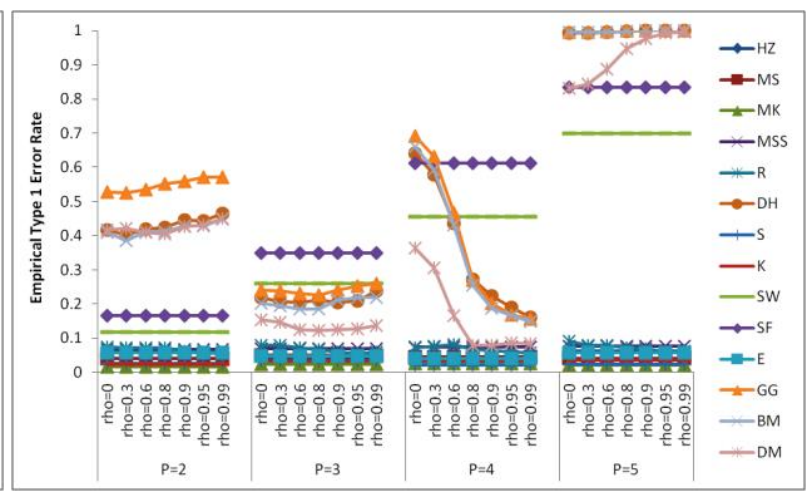

(d) $\quad \mathrm{n}=50$ at $\alpha=0.05$

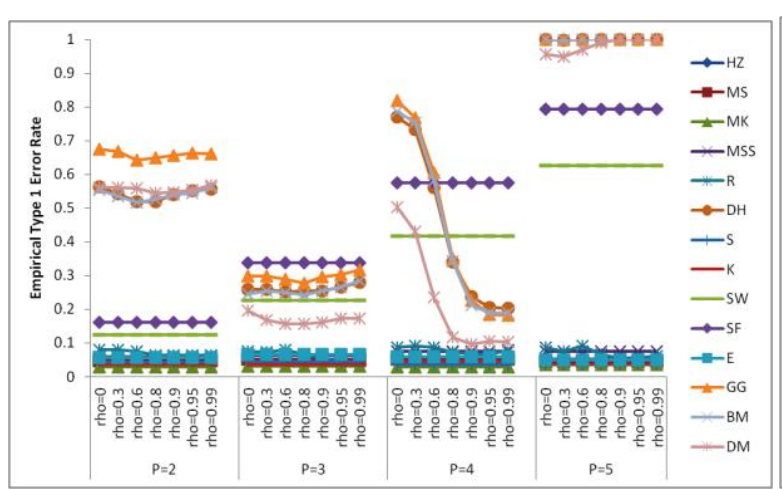

(e) $\mathrm{n}=75$ at $\alpha=0.05$

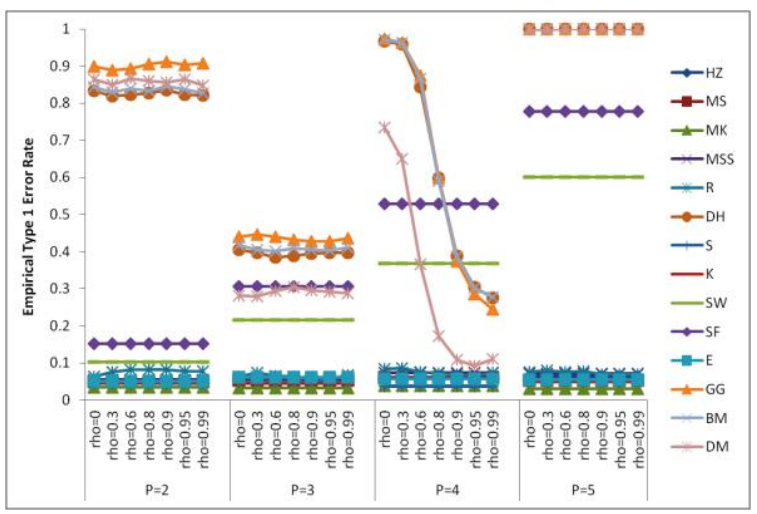

(g) $\mathrm{n}=150$ at $\alpha=0.05$

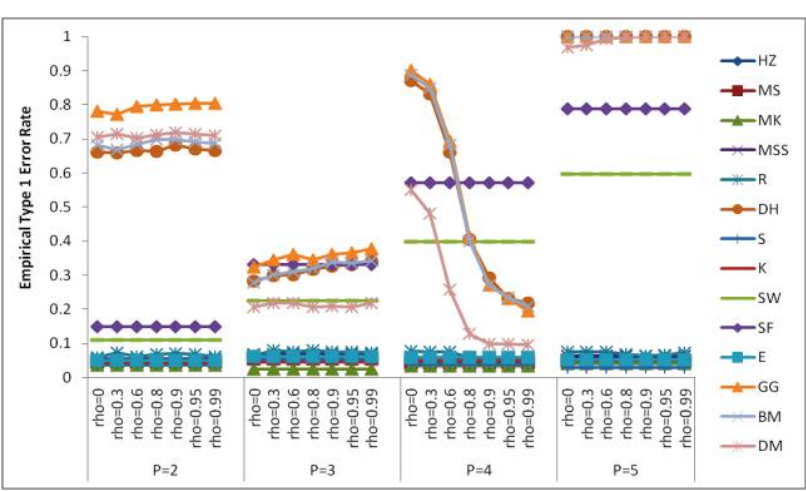

(f) $\mathrm{n}=100$ at $\alpha=0.05$

Figure 2: Comparison of Type 1 Error Rates of Multivariate Normality Tests in the Presence of Correlation at 0.05 Level of Significance 
Table 3: Sample of Empirical Type 1 Error Rate for Comparison of Multivariate Normality Tests at $5 \%$ Level of Significance

\begin{tabular}{|c|c|c|c|c|c|c|c|c|c|}
\hline \multicolumn{2}{|c|}{ Sample Size } & \multicolumn{4}{|c|}{10} & \multicolumn{4}{|c|}{20} \\
\hline Test & plrho & 0 & 0.6 & 0.9 & 0.99 & 0 & 0.6 & 0.9 & 0.99 \\
\hline \multirow{3}{*}{$\mathrm{HZ}$} & 2 & 0.035 & 0.035 & 0.035 & 0.035 & 0.039 & 0.039 & 0.039 & 0.039 \\
\hline & 3 & 0.032 & 0.032 & 0.032 & 0.032 & 0.038 & 0.038 & 0.038 & 0.038 \\
\hline & 4 & 0.034 & 0.034 & 0.034 & 0.034 & 0.032 & 0.032 & 0.032 & 0.032 \\
\hline \multirow{3}{*}{ MS } & 2 & 0.004 & 0.004 & 0.004 & 0.004 & 0.029 & 0.029 & 0.029 & 0.029 \\
\hline & 3 & 0 & 0 & 0 & 0 & 0.015 & 0.015 & 0.015 & 0.015 \\
\hline & 4 & 0 & 0 & 0 & 0 & 0.011 & 0.011 & 0.011 & 0.011 \\
\hline \multirow{3}{*}{ MK } & 2 & 0 & 0 & 0 & 0 & 0.007 & 0.007 & 0.007 & 0.007 \\
\hline & 3 & 0 & 0 & 0 & 0 & 0.001 & 0.001 & 0.001 & 0.001 \\
\hline & 4 & 0 & 0 & 0 & 0 & 0 & 0 & 0 & 0 \\
\hline \multirow{3}{*}{ MSS } & 2 & 0.052 & 0.052 & 0.052 & 0.052 & 0.061 & 0.061 & 0.061 & 0.061 \\
\hline & 3 & 0.042 & 0.042 & 0.042 & 0.042 & 0.064 & 0.064 & 0.064 & 0.064 \\
\hline & 4 & 0.025 & 0.025 & 0.025 & 0.025 & 0.063 & 0.063 & 0.063 & 0.063 \\
\hline \multirow{3}{*}{$\mathrm{R}$} & 2 & 0.062 & 0.072 & 0.066 & 0.07 & 0.052 & 0.061 & 0.072 & 0.072 \\
\hline & 3 & 0.057 & 0.054 & 0.063 & 0.064 & 0.073 & 0.069 & 0.068 & 0.073 \\
\hline & 4 & 0.058 & 0.061 & 0.053 & 0.058 & 0.07 & 0.08 & 0.072 & 0.063 \\
\hline \multirow{3}{*}{$\mathrm{DH}$} & 2 & 0.16 & 0.149 & 0.168 & 0.159 & 0.266 & 0.24 & 0.248 & 0.247 \\
\hline & 3 & 0.096 & 0.087 & 0.08 & 0.077 & 0.141 & 0.119 & 0.14 & 0.144 \\
\hline & 4 & 0.206 & 0.143 & 0.075 & 0.054 & 0.322 & 0.217 & 0.122 & 0.108 \\
\hline \multirow{3}{*}{$\mathrm{S}$} & 2 & 0.001 & 0.001 & 0.001 & 0.001 & 0.021 & 0.021 & 0.021 & 0.021 \\
\hline & 3 & 0 & 0 & 0 & 0 & 0.011 & 0.011 & 0.011 & 0.011 \\
\hline & 4 & 0 & 0 & 0 & 0 & 0.003 & 0.003 & 0.003 & 0.003 \\
\hline \multirow{3}{*}{$\mathrm{K}$} & 2 & 0 & 0 & 0 & 0 & 0.012 & 0.012 & 0.012 & 0.012 \\
\hline & 3 & 0 & 0 & 0 & 0 & 0.003 & 0.003 & 0.003 & 0.003 \\
\hline & 4 & 0 & 0 & 0 & 0 & 0.002 & 0.002 & 0.002 & 0.002 \\
\hline \multirow{3}{*}{ SW } & 2 & 0.162 & 0.162 & 0.162 & 0.162 & 0.117 & 0.117 & 0.117 & 0.117 \\
\hline & 3 & 0.44 & 0.44 & 0.44 & 0.44 & 0.335 & 0.335 & 0.335 & 0.335 \\
\hline & 4 & 0.791 & 0.791 & 0.791 & 0.791 & 0.586 & 0.586 & 0.586 & 0.586 \\
\hline \multirow{3}{*}{ SF } & 2 & 0.217 & 0.217 & 0.217 & 0.217 & 0.172 & 0.172 & 0.172 & 0.172 \\
\hline & 3 & 0.544 & 0.544 & 0.544 & 0.544 & 0.452 & 0.452 & 0.452 & 0.452 \\
\hline & 4 & 0.886 & 0.886 & 0.886 & 0.886 & 0.712 & 0.712 & 0.712 & 0.712 \\
\hline \multirow{3}{*}{$\mathrm{E}$} & 2 & 0.049 & 0.049 & 0.049 & 0.049 & 0.042 & 0.042 & 0.042 & 0.042 \\
\hline & 3 & 0.05 & 0.05 & 0.05 & 0.05 & 0.044 & 0.044 & 0.044 & 0.044 \\
\hline & 4 & 0.058 & 0.058 & 0.058 & 0.058 & 0.036 & 0.036 & 0.036 & 0.036 \\
\hline \multirow{3}{*}{ GG } & 2 & 0.203 & 0.197 & 0.215 & 0.224 & 0.337 & 0.282 & 0.328 & 0.325 \\
\hline & 3 & 0.127 & 0.104 & 0.096 & 0.081 & 0.173 & 0.138 & 0.149 & 0.15 \\
\hline & 4 & 0.243 & 0.147 & 0.075 & 0.056 & 0.363 & 0.247 & 0.104 & 0.094 \\
\hline \multirow{3}{*}{$\mathrm{BM}$} & 2 & 0.08 & 0.071 & 0.093 & 0.088 & 0.189 & 0.179 & 0.186 & 0.183 \\
\hline & 3 & 0.057 & 0.043 & 0.051 & 0.047 & 0.113 & 0.095 & 0.096 & 0.114 \\
\hline & 4 & 0.16 & 0.095 & 0.036 & 0.037 & 0.289 & 0.184 & 0.085 & 0.081 \\
\hline \multirow{3}{*}{ DM } & 2 & 0.128 & 0.11 & 0.112 & 0.108 & 0.216 & 0.181 & 0.178 & 0.198 \\
\hline & 3 & 0.088 & 0.051 & 0.041 & 0.044 & 0.097 & 0.069 & 0.073 & 0.078 \\
\hline & 4 & 0.124 & 0.063 & 0.05 & 0.041 & 0.195 & 0.096 & 0.052 & 0.057 \\
\hline
\end{tabular}

Source: Simulation Results available in [19] 


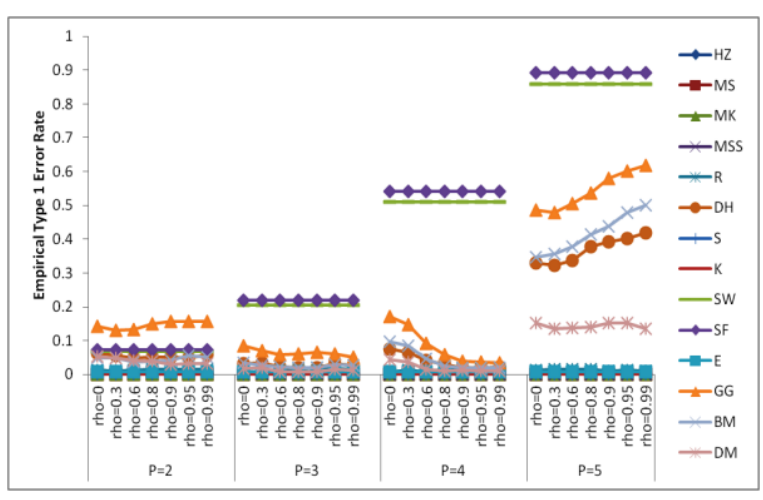

(a) $\mathrm{n}=10$ at $\alpha=0.01$

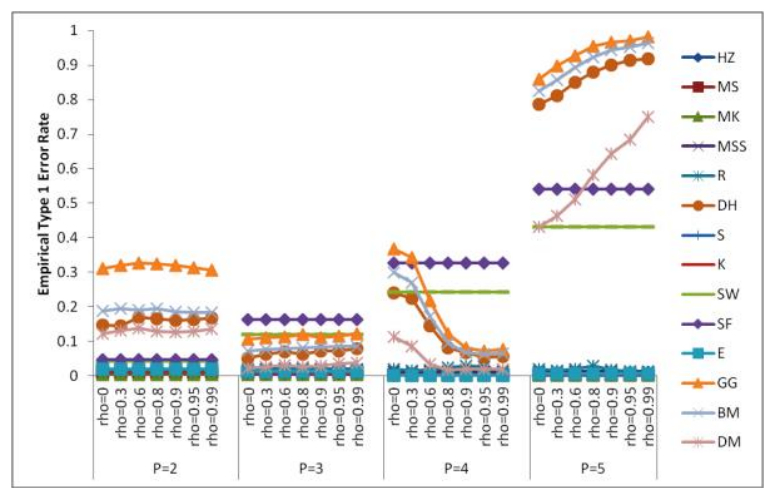

(c) $\mathrm{n}=30$ at $\alpha=0.01$

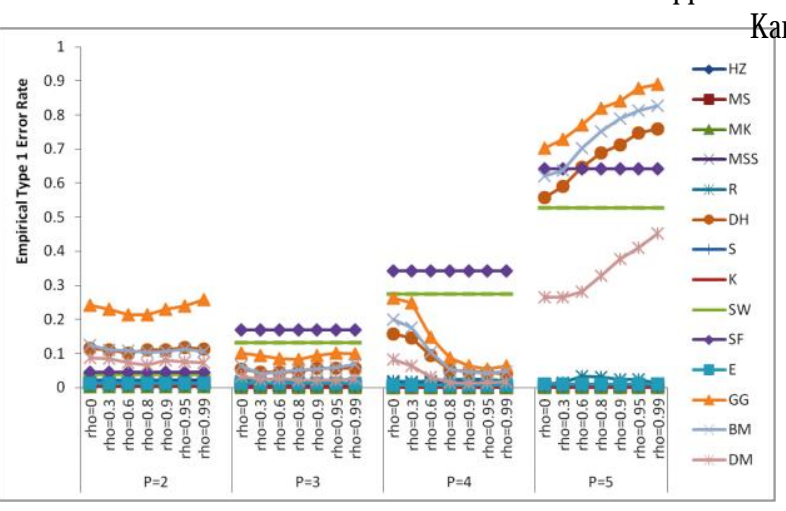

(b) $\mathrm{n}=20$ at $\alpha=0.01$ Kansas State University

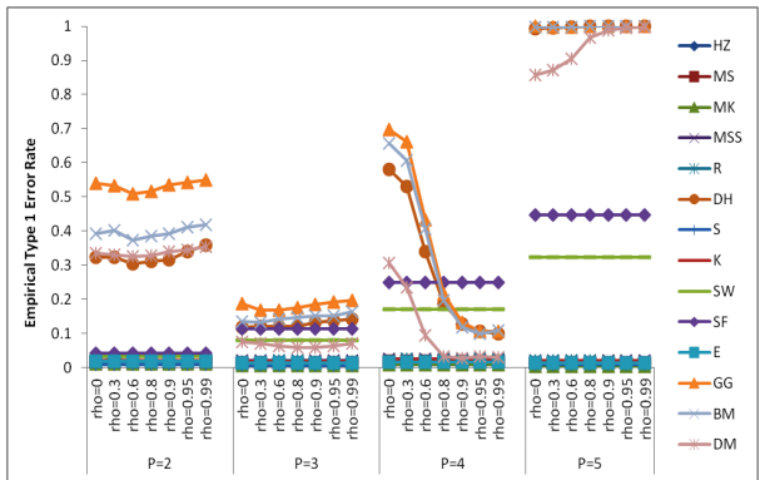

(e) $\mathrm{n}=75$ at $\alpha=0.01$

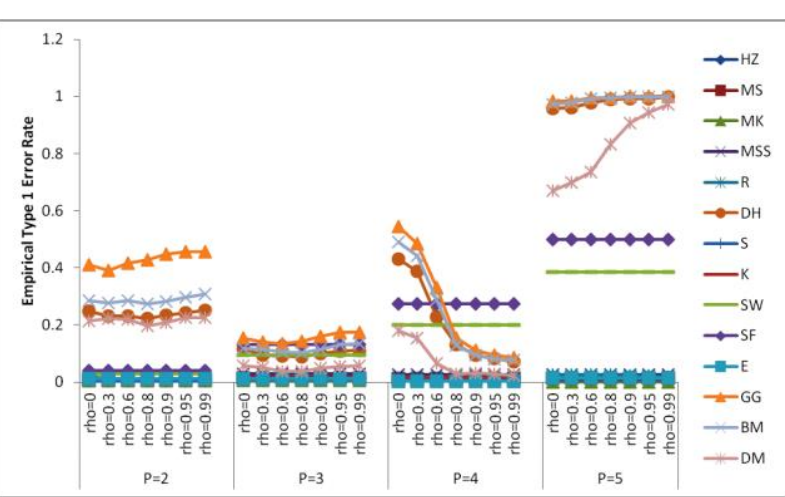

(d) $\quad \mathrm{n}=50$ at $\alpha=0.01$

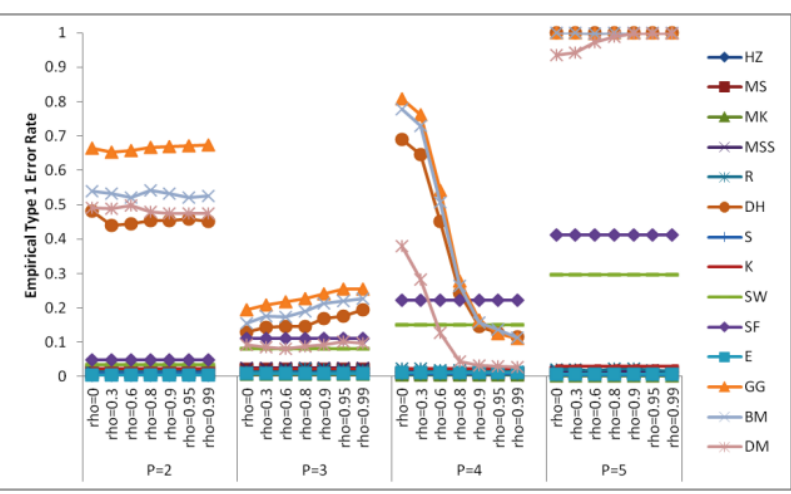

(f) $\mathrm{n}=100$ at $\alpha=0.01$

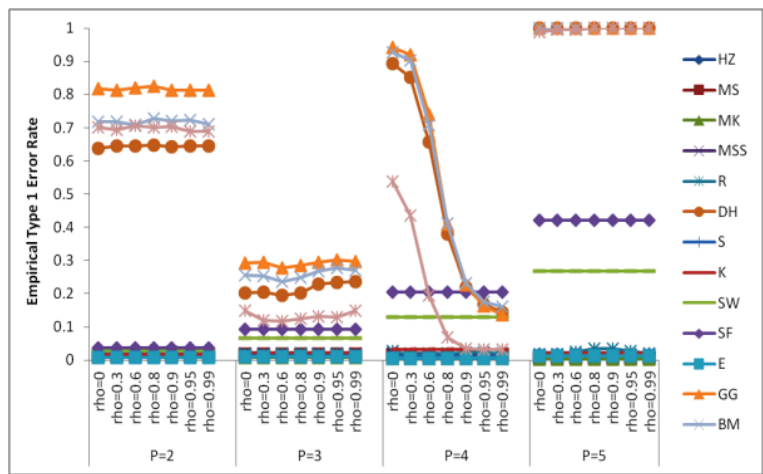

(g) $\mathrm{n}=150$ at $\alpha=0.01$

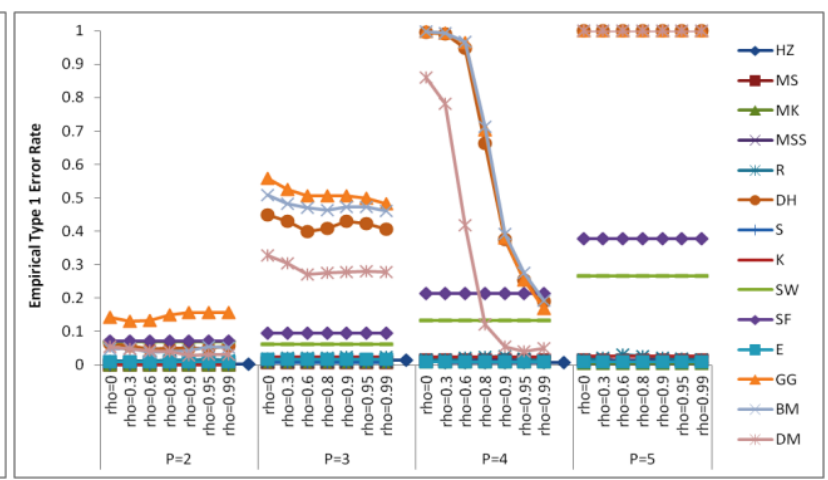

(h) $\mathrm{n}=300$ at $\alpha=0.01$

Figure 3: Comparison of Type 1 Error Rates of Multivariate Normality Tests in the Presence of Correlation at 0.01 Level of Significance 
Table 4: Sample of Empirical Type 1 Error Rate for Comparison of Multivariate Normality Kansas State University $1 \%$ Level of Significance

\begin{tabular}{|c|c|c|c|c|c|c|c|c|c|}
\hline \multicolumn{2}{|c|}{ Sample Size } & \multicolumn{4}{|c|}{10} & \multicolumn{4}{|c|}{20} \\
\hline Test & płrho & 0 & 0.6 & 0.9 & 0.99 & 0 & 0.6 & 0.9 & 0.99 \\
\hline \multirow{3}{*}{$\mathrm{HZ}$} & 2 & 0.002 & 0.002 & 0.002 & 0.002 & 0.008 & 0.008 & 0.008 & 0.008 \\
\hline & 3 & 0.004 & 0.004 & 0.004 & 0.004 & 0.007 & 0.007 & 0.007 & 0.007 \\
\hline & 4 & 0.003 & 0.003 & 0.003 & 0.003 & 0.005 & 0.005 & 0.005 & 0.005 \\
\hline \multirow{3}{*}{ MS } & 2 & 0.001 & 0.001 & 0.001 & 0.001 & 0.012 & 0.012 & 0.012 & 0.012 \\
\hline & 3 & 0 & 0 & 0 & 0 & 0.005 & 0.005 & 0.005 & 0.005 \\
\hline & 4 & 0 & 0 & 0 & 0 & 0.001 & 0.001 & 0.001 & 0.001 \\
\hline \multirow{3}{*}{ MK } & 2 & 0 & 0 & 0 & 0 & 0.002 & 0.002 & 0.002 & 0.002 \\
\hline & 3 & 0 & 0 & 0 & 0 & 0 & 0 & 0 & 0 \\
\hline & 4 & 0 & 0 & 0 & 0 & 0 & 0 & 0 & 0 \\
\hline \multirow{3}{*}{ MSS } & 2 & 0.01 & 0.01 & 0.01 & 0.01 & 0.022 & 0.022 & 0.022 & 0.022 \\
\hline & 3 & 0.003 & 0.003 & 0.003 & 0.003 & 0.012 & 0.012 & 0.012 & 0.012 \\
\hline & 4 & 0.001 & 0.001 & 0.001 & 0.001 & 0.015 & 0.015 & 0.015 & 0.015 \\
\hline \multirow{3}{*}{$\mathrm{R}$} & 2 & 0.013 & 0.013 & 0.014 & 0.015 & 0.016 & 0.019 & 0.02 & 0.015 \\
\hline & 3 & 0.004 & 0.01 & 0.02 & 0.014 & 0.018 & 0.021 & 0.015 & 0.012 \\
\hline & 4 & 0.009 & 0.007 & 0.017 & 0.016 & 0.018 & 0.019 & 0.023 & 0.019 \\
\hline \multirow{3}{*}{$\mathrm{DH}$} & 2 & 0.063 & 0.048 & 0.051 & 0.058 & 0.114 & 0.102 & 0.111 & 0.112 \\
\hline & 3 & 0.033 & 0.023 & 0.021 & 0.028 & 0.054 & 0.046 & 0.056 & 0.057 \\
\hline & 4 & 0.076 & 0.041 & 0.019 & 0.022 & 0.157 & 0.094 & 0.048 & 0.039 \\
\hline \multirow{3}{*}{$\mathrm{S}$} & 2 & 0 & 0 & 0 & 0 & 0.005 & 0.005 & 0.005 & 0.005 \\
\hline & 3 & 0 & 0 & 0 & 0 & 0 & 0 & 0 & 0 \\
\hline & 4 & 0 & 0 & 0 & 0 & 0.001 & 0.001 & 0.001 & 0.001 \\
\hline \multirow{3}{*}{ K } & 2 & 0 & 0 & 0 & 0 & 0.003 & 0.003 & 0.003 & 0.003 \\
\hline & 3 & 0 & 0 & 0 & 0 & 0.001 & 0.001 & 0.001 & 0.001 \\
\hline & 4 & 0 & 0 & 0 & 0 & 0 & 0 & 0 & 0 \\
\hline \multirow{3}{*}{ SW } & 2 & 0.069 & 0.069 & 0.069 & 0.069 & 0.038 & 0.038 & 0.038 & 0.038 \\
\hline & 3 & 0.204 & 0.204 & 0.204 & 0.204 & 0.131 & 0.131 & 0.131 & 0.131 \\
\hline & 4 & 0.511 & 0.511 & 0.511 & 0.511 & 0.274 & 0.274 & 0.274 & 0.274 \\
\hline \multirow{3}{*}{$\mathrm{SF}$} & 2 & 0.072 & 0.072 & 0.072 & 0.072 & 0.045 & 0.045 & 0.045 & 0.045 \\
\hline & 3 & 0.219 & 0.219 & 0.219 & 0.219 & 0.17 & 0.17 & 0.17 & 0.17 \\
\hline & 4 & 0.541 & 0.541 & 0.541 & 0.541 & 0.342 & 0.342 & 0.342 & 0.342 \\
\hline \multirow{3}{*}{$\mathrm{E}$} & 2 & 0.009 & 0.009 & 0.009 & 0.009 & 0.012 & 0.012 & 0.012 & 0.012 \\
\hline & 3 & 0.009 & 0.009 & 0.009 & 0.009 & 0.012 & 0.012 & 0.012 & 0.012 \\
\hline & 4 & 0.007 & 0.007 & 0.007 & 0.007 & 0.008 & 0.008 & 0.008 & 0.008 \\
\hline \multirow{3}{*}{ GG } & 2 & 0.143 & 0.134 & 0.158 & 0.157 & 0.242 & 0.213 & 0.231 & 0.257 \\
\hline & 3 & 0.084 & 0.059 & 0.066 & 0.051 & 0.1 & 0.085 & 0.095 & 0.099 \\
\hline & 4 & 0.172 & 0.093 & 0.039 & 0.034 & 0.262 & 0.149 & 0.064 & 0.064 \\
\hline \multirow{3}{*}{$\mathrm{BM}$} & 2 & 0.048 & 0.038 & 0.042 & 0.052 & 0.124 & 0.107 & 0.105 & 0.106 \\
\hline & 3 & 0.035 & 0.023 & 0.021 & 0.027 & 0.064 & 0.045 & 0.054 & 0.069 \\
\hline & 4 & 0.097 & 0.047 & 0.019 & 0.019 & 0.2 & 0.104 & 0.045 & 0.048 \\
\hline \multirow{3}{*}{$\mathrm{DM}$} & 2 & 0.054 & 0.042 & 0.029 & 0.032 & 0.088 & 0.072 & 0.08 & 0.074 \\
\hline & 3 & 0.018 & 0.009 & 0.008 & 0.012 & 0.034 & 0.026 & 0.022 & 0.027 \\
\hline & 4 & 0.044 & 0.015 & 0.013 & 0.011 & 0.082 & 0.03 & 0.012 & 0.016 \\
\hline
\end{tabular}

Source: Simulation Result available in [19] 
Table 5: Total Number of Times Type 1 Error Rate Approximates True Value Over All Levels Significance, Levels Dimension and Correlation

\begin{tabular}{|c|c|c|c|c|c|c|c|c|c|c|}
\hline \multirow[b]{2}{*}{ Tests } & \multicolumn{8}{|c|}{ Sample Size } & \multirow[b]{2}{*}{ Total } & \multirow[b]{2}{*}{ Rank } \\
\hline & 10 & 20 & 30 & 50 & 75 & 100 & 150 & 300 & & \\
\hline $\mathrm{HZ}$ & 21 & 49 & 42 & 49 & 56 & 55 & 49 & 63 & 384 & 2 \\
\hline MS & 0 & 14 & 28 & 42 & 56 & 49 & 49 & 22 & 260 & 5 \\
\hline MK & 0 & 0 & 0 & 14 & 21 & 14 & 21 & 35 & 105 & 7 \\
\hline MSS & 21 & 41 & 43 & 35 & 28 & 35 & 28 & 49 & 280 & 3 \\
\hline $\mathrm{R}$ & 49 & 32 & 28 & 34 & 33 & 41 & 24 & 34 & 275 & 4 \\
\hline $\mathrm{DH}$ & 12 & 0 & 0 & 0 & 0 & 0 & 0 & 0 & 12 & 11 \\
\hline $\mathrm{S}$ & 0 & 7 & 7 & 21 & 28 & 28 & 42 & 28 & 161 & 6 \\
\hline K & 0 & 0 & 14 & 14 & 0 & 14 & 14 & 28 & 84 & 8 \\
\hline SW & 0 & 0 & 0 & 0 & 0 & 0 & 0 & 0 & 0 & 13.5 \\
\hline SF & 0 & 0 & 0 & 0 & 0 & 0 & 0 & 0 & 0 & 13.5 \\
\hline $\mathrm{E}$ & 77 & 49 & 42 & 49 & 49 & 70 & 63 & 56 & 455 & 1 \\
\hline GG & 7 & 2 & 0 & 0 & 0 & 0 & 0 & 0 & 9 & 12 \\
\hline $\mathrm{BM}$ & 10 & 5 & 0 & 0 & 0 & 0 & 0 & 0 & 15 & 10 \\
\hline DM & 19 & 12 & 5 & 2 & 0 & 0 & 0 & 0 & 38 & 9 \\
\hline
\end{tabular}

Source: Counted from Simulation Results available in [19]

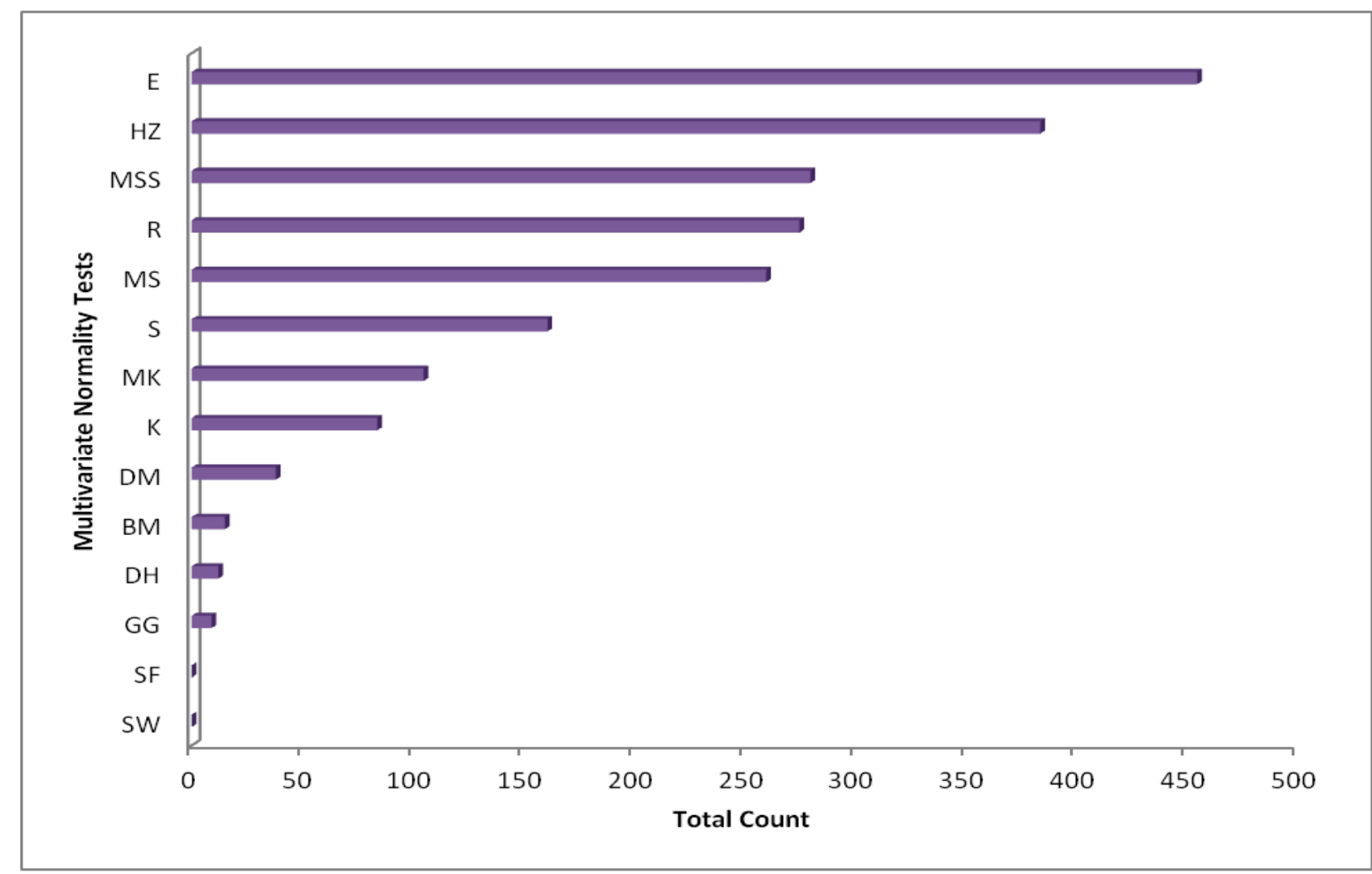

Figure 4: Bar Chart Showing Total Number of Times Type 1 Error Rate Approximates True Value Over All Significance Levels, Dimensions and Correlations 
The effect of correlations was examined on the Type 1 error rates of the multivariate tests of normality. The study revealed that the Type 1 error rates of $\mathrm{R}, \mathrm{DH}, \mathrm{GG}, \mathrm{BM}$ and $\mathrm{DM}$ tests are affected by correlation while those of HZ, MS, MK, MSS, S, K, SW, SF and E tests are not affected by correlation. Type 1 error rates of tests affected by correlations are comparatively bad except that of $\mathrm{R}$ whereas those of tests not affected by correlation revolve around the true levels of significance except that of SW and SF.MS, R, MSS, HZ and E tests, in this order, have good Type 1 error rates Hence, E and HZ tests are therefore identified to have best Type 1 error rates in the presence of correlations. They are therefore recommended for practitioners.

This conclusion and recommendation are limited to the fact that no standard comparison was used. However, comparisons are only based on preferred intervals and frequency of counts.

\section{References}

[1] C. J. Mecklin and D. J. Mundfrom, "On Using Asymptotic Critical Values in Testing for Multivariate Normality, Interstat," 2003. [Online]. Available: http://interstat.statjournals.net/YEAR/2003/abstracts/0301001.php. [Accessed 30 June 2015].

[2] J. A. Doornik and D. Harsen, An Omnibus Test for Univariate and Multivariate Normality, vol. 70, Working Paper: Nuffield College, Oxford, 1994, pp. 927-939.

[3] S. S. Shapiro and R. S. Francia, "An Approximate Analysis of Variance Test of Normality," Journal of the American Statistical Association, vol. 67, pp. 215-216, 1972.

[4] K. Mardia, "Measures of Multivariate Skewness and Kurtosis with Applications," Biometrika, vol. 57, pp. 519-530, 1970.

[5] A. Kankainen, S. Taskinen and H. Oja, "Tests of multinormality based on location vectors and scatter matrices," Stat. Methods Appl., vol. 16, no. 3, pp. 375-379, 2007.

[6] S. S. Shapiro and M. B. Wilk, "An analysis of variance test for normality",Biometrika, vol. 52, pp. 591-611, 1965.

[7] J. P. Royston, "An extension of Shapiro and Wilk's W Test for Normality to Large Samples," Applied Statistics, vol. 31, no. 2, pp. 115-124, 1982.

[8] A. Desgagné, P. L. Micheaux and A. Leblanc, "Test of normality against generalized exponential power alternatives," Communications in Statistics - Theory and Methods, vol. 42, no. 1, pp. 164-190, 2013.

[9] N. Henze and B. Zirkler, "A class of invariant consistent tests for Multivariate Normality," Communs. Statist. Theory Mech., vol. 19, pp. 3595-3618, 1990.

[10] G. J. Szekely and M. L. Rizzo, "A New Test for Multivariate Normality," Journal of Multivariate Analysis, vol. 93, no. 1, pp. 58-80, 2005.

[11] Y. R. Gel and J. L. Gastwirth, "A Robust Modification of the Jarque-Bera Test of Normality," Econom. Lett., vol. 99, no. 1, pp. 30-32, 2008. 
[12] C. Bontemps and N. Meddahi, "Testing Normality: a GMM Approach," J. Econom., vol. 124, no. 1, pp. 149-186, 2005.

[13] K. Ayinde, G. S. Solomon and A. O. Adejumo, "A Comparative Study of the Type 1 Error Rates of Some Multivariate Tests of Normality," Mathematical Physics, vol. 34, no. 1, pp. 185198, 2016.

[14] K. Mardia, J. Kent and J. Bibby, Multivariate Analysis, London: Academic Press, 1979.

[15] N. Henze and B. Zirkler, "A class of invariant consistent tests for Multivariate Normality," Communs. Statist. Theory Mech., vol. 19, pp. 3595-3618, 1990.

[16] J. P. Royston, "Some Techniques for Assessing Multivariate Normality Based on the ShapiroWilk W," Applied Statistics, vol. 32, no. 2, pp. 121-133, 1983.

[17] D. Czeslaw, "Attempt to assess Multivariate Normality Tests," Folia Oeconomica, vol. 235, pp. 75-86, 2010.

[18] K. Ayinde and O. S. Adegboye, "Equations for Generating Normally Distributed Random Variables with Specified Intercorrelation," Journal of Mathematical Sciences, vol. 21, no. 2, pp. 183-203, 2010.

[19] G. S. Solomon, "Comparative Study of the Type 1 Error and Power Rates of Some Multivariate Tests of Normality," Unpublished M.Tech. Thesis, Department of Statistics, Ladoke Akintola University of Technology, Ogbomoso, 2016.

[20] R Developmet Core Team, "R Development Core Team," 2016. [Online]. Available: https://www.r-project.org/.

[21] J. O. Kuranga, Type 1 Error Rate and Power Comparison of Some Normality Test Statistics, Ogbomoso: Unpublished M.Phil. Thesis, Department of Statistics, Ladoke Akintola University of Technology, 2015. 